\title{
O PAPEL DOS SERVIÇOS FINANCEIROS RURAIS NA PROMOÇÃO DO DESENVOLVIMENTO DA AGRICULTURA FAMILIAR: CaSo da Cooperativa 25 de Setembro no distrito de Boane, Moçambique
}

\author{
José de Sousa Paiva Moura ${ }^{1}$ \\ Nelson Maria Rosário ${ }^{2}$
}

\section{Resumo}

Em Moçambique, a agricultura familiar é o sector que emprega a maioria da população e nos últimos anos essa atividade tem sido deixada a deriva e, em contrapartida, os outros sectores são privilegiados, mesmo quando se sabe que a agricultura é considerada a principal atividade econômica. $\mathrm{O}$ presente artigo tem como objetivo analisar o papel dos serviços financeiros rurais na promoção do desenvolvimento da agricultura familiar, caso da Cooperativa 25 de Setembro no distrito de Boane, mostrando ainda que os serviços financeiros são importantes na ajuda as familias rurais para terem uma vida mais digna. Para a concretização do objetivo, recorreu-se a pesquisa exploratória, qualitativa e quantitativa e estudo de caso, suportados pela pesquisa bibliográfica e documental. Os resultados mostram que os serviços financeiros rurais promovem o desenvolvimento da agricultura familiar, na Cooperativa em particular e no distrito em geral.

Palavras-chave: Agricultura familiar, Serviços financeiros rurais ePromoção do desenvolvimento

\section{THE ROLE OF THE RURAL FINANCE IN DEVELOPMENT PROMOTION OF FAMILY AGRICULTURE: Study case Cooperative 25 de September in Boane district, Mozambique}

\begin{abstract}
In Mozambique, family agriculture is a sector which employs the huge number of the population and in the past years, this activity is being misled and on the other hand other sectors are taking in consideration even through is known that the agriculture is consider the backbone of the economy. This article has the main objective to analyses the role of the rural finance in development promotion of family agriculture study case Cooperative 25 de September in Boane district, showing that the financial services are important in helping rural families to lead a more dignified life. In order to make the objective come through, a exploratory research has taken place on the study case as well as quantitative and qualitative

\footnotetext{
${ }^{1}$ Licenciado em Agro-Negócios na Escola Superior de Negócios e Empreendedorismo de Chibuto da Universidade Eduardo Mondlane. Contacto: josopamo@gmail.com

2 Professor na Escola Superior de Negócios e Empreendedorismo de Chibuto da Universidade Eduardo Mondlane. Contacto: nemaro17@gmail.com
} 
supported by bibliography and documental research. The results show that rural financial promotes development of family agriculture in cooperative either in particular Boane district."

Keywords:Familyagriculture, financial rural services anddevelopment promotion

\section{EL PAPEL DE LOS SERVICIOS FINANCIEROS RURALES EN LA PROMOCIÓN DEL DESARROLLO DE LA AGRICULTURA FAMILIAR: Si la Cooperativa 25 de septiembre en el distrito Boane, Mozambique}

\section{Resumen}

En Mozambique, la agricultura familiar es el sector que emplea a la mayoría de la población y en los últimos años esta actividad ha permitido a la deriva y, por otro lado, otros sectores son privilegiados, aun cuando se sabe que la agricultura es considerada la principal actividad económica. Este artículo tiene como objetivo analizar el papel de los servicios financieros rurales en la promoción del desarrollo de la agricultura familiar, si la Cooperativa 25 de septiembre en el distrito Boane, sigue mostrando que los servicios financieros son importantes para ayudar a las familias rurales a tener una vida más digna. Para lograr el objetivo, se utilizó el estudio de investigación y de caso exploratorio, cualitativo y cuantitativo, con el apoyo documental y la investigación bibliográfica. Los resultados muestran que los servicios financieros rurales promueven el desarrollo de la agricultura familiar, cooperativa, en particular, y el distrito en general.

Palabras clave: agricultura familiar, los servicios financieros rurales y que promueven el desarrollo

\section{INTRODUÇÃO}

Os serviços financeiros constituem uma espinha dorsal para a efetividade da atividade agrícola no país e o motor que guia a atividade comercial com vista a sua lucratividade. Como em qualquer parte do mundo, estes serviços são prestados e ou destinados a determinados grupos, estando os pequenos produtores inclusos.

Com o financiamento da agricultura, neste caso a familiar ${ }^{3}$ poderá se dar o inicio a mudança de paradigma, passando-se da produção rudimentar que até hoje predomina em Moçambique para a agricultura moderna, fazendo nesse caso com que haja aumento dosíndices de produção e produtividade. Considera-semodernização da agricultura em Moçambique quando há essencialmente o emprego de maquinarias e uso de agro-químicos para a produção agrícola. Importa referir, que esta modernização ainda está longe de se tornar

\footnotetext{
3،São considerados, como tal, os produtores agrários de pequena escala, cuja produção é intensiva em mãodeobra, sobretudo familiar, pouco integrados no mercado de factores (insumos, máquinas e dinheiro - terra, trabalho assalariado e outras fontes de rendimento não-agrícola), que produzem, essencialmente, para a reprodução da família”(MOSCA, 2014,p. 4).
} 
real, visto que ela continua a ser praticada na grande maioria ainda de uma forma tradicional, não existindo deste modomão-de-obracom conhecimento suficiente e capaz de dar conta da produção e as necessidades da procura.

A agricultura familiar ${ }^{4}$ é uma atividade que faz face às necessidades e dificuldades de consumo de bens para a maioria da população mundial pelo fato de prover produtos relativamente acessíveis e deste modo, substituindo os disponibilizados pelos supermercados que pela sua característica já são relativamente onerosos. O nosso país debate-se imensamente com a problemática de chuvas bastante irregulares, falta de aproveitamento e capacidades de irrigação das áreas de cultivo, cheias que inundam os campos e secas, todos esses fenómenos ocorrem de forma cíclica, fraco acesso aos serviços agrários, incluindo tecnologias melhoradas e serviços financeiros, o que no final da época produtiva se traduz em baixa produção e produtividade agrícolas. (CUNGUARA\&GARRETT 2011)

Portanto, fica assente que a agricultura familiar é toda aquela atividade produtiva praticada pelos pequenos produtores moçambicanos ou famílias moçambicanas, usando técnicas rudimentares de produção.

O estudo versa sobre "O papel dos serviços financeiros rurais na promoção do desenvolvimento da agricultura familiar, o mesmo tem como objeto de estudo a Cooperativa 25 de Setembro ${ }^{5}$, instalada no distrito de Boane Sede, província de Maputo, Moçambique. Nesta perspectiva, o estudo pode ser considerado de extrema relevância pelo facto da agricultura ser fortemente praticada e ao mesmo tempo empregar a maioria da população moçambicana, sendo assim responsável pelo suporte alimentar da população. Contudo, este setor debate-se além dos problemas acima referenciados, com o difícil acesso aos serviços financeiros que jogam um papel fundamental, uma vez que poderá ajudar na melhoria dos índices de produtividade e consequentemente minimizará o já crónico problema da insegurança alimentar que ocorre quase de uma forma cíclica no país. Por estas e mais razões implícitas, surgiu o interesse em perceber o facto de a atividade agrícola ser posta de lado

\footnotetext{
4، A agricultura familiar em Moçambique constitui a actividade económica que ocupa grande parte da população, podendo alcançar mais de $75 \%$ dos cidadãos.Em Moçambique a agricultura familiar é constituída essencialmente por pequenas explorações cultivando em áreas de até cinco hectares” (SITOE, 2005, p. 5)

${ }^{5}$ A cooperativa 25 de Setembro tem como principal atividade a produção agrícola e comercialização agrícola, tem na pecuária uma atividade complementar, dedicando-se na criação de suínos. A cooperativa disponibiliza terra, meios e insumos de produção para seus associados cultivarem, garante assistência técnica e formação junto do Governo ou das organizações não governamentais.
} 
quando se fala do acesso aos serviços financeiros, mesmo sabendo que a agricultura é a base do desenvolvimento do país.

Em termos metodológicos, fez-se um estudo exploratório quanto aos objetivos, qualitativo e quantitativo quanto ao tipo de pesquisa e fez-se um estudo de caso com uma abordagem indutiva.

\section{Serviços financeiros rurais e os seus respectivos agentes fornecedores/provedores}

Serviços financeiros são atividades não relacionadas com a obtenção de recursos e concessão de créditos, sendo que a sua remuneração é definida por um valor e ou percentual fixo e pré-determinado sobre o valor envolvido no serviço. (DANTAS, 1994 como citado em Dicionário Sensagent ${ }^{6}$.

De acordo com Cobra (2000) como citado em Dicionário Sensagent, serviços financeiros são os serviços prestados pelas instituições financeiras.

Serviços financeiros englobam essencialmente as atividades da banca e seguros, fundamentais para a sustentação da economia nacional, não só em termos diretos, pela capacidade geradora de emprego e riqueza, como indirectamente, pelo apoio que prestam às empresas no desenvolvimento do seu negócio. (LEADERSHIP BUSINESS GROUP, 2016).

De acordo com Brealey, Myers \& Allen (2007), as instituições financeiras são os bancos, empresas de poupança e de empréstimos, as seguradoras e os fundos de investimento. Em Moçambique os fornecedores ou prestadores de serviços financeiros são de acordo com Amarcy e Massingue (2011), as instituições de crédito constituídas por bancos comerciais e de investimento, cooperativas de crédito, micro-bancos e instituições de locação financeira. Grob e Nogueira (2010) apontam uma série de instituições que fornecem serviços financeiros (Quadro 1).

Segundo a Lei 9/2004 de 21 de Julho, as cooperativas de crédito são instituições de crédito constituídas na forma de sociedades cooperativas, cuja atividade desenvolve-sea serviço exclusivo dos seus sócios. Esta lei vê o crédito como o ato pelo qual uma entidade, agindo a título oneroso, coloca ou promete colocar fundos à disposição de outra entidade contra a promessa de esta a restituir na data de vencimento, ou contrair, no interesse da mesma, uma obrigação por assinatura.

\footnotetext{
${ }^{6}$ Dicionário onlineconsultado em: http://dicionario.sensagent.com/francisco\%20Dantas/pt-pt 
Quadro 1: Prestadores ou provedores de serviços financeiros

\begin{tabular}{|c|c|c|c|}
\hline Bancos Comerciais & $\begin{array}{c}\text { Bancos de } \\
\text { Microfinanças }\end{array}$ & $\begin{array}{l}\text { Operadores de } \\
\text { Microfinanças }\end{array}$ & $\begin{array}{c}\text { Instituições } \\
\text { Financeiras de } \\
\text { Desenvolvimento }\end{array}$ \\
\hline $\begin{array}{l}\text { Banco Comercial e de } \\
\text { Investimentos, SA (BCI) }\end{array}$ & $\begin{array}{l}\text { Banco } \\
\text { Oportunidade de } \\
\text { Moçambique, SA } \\
(\mathrm{BOM})\end{array}$ & $\begin{array}{l}\text { Agência de } \\
\text { Desenvolvimento } \\
\text { Econômico da Província de } \\
\text { Manica (ADEM) }\end{array}$ & ADIPSA \\
\hline BancABC, SA & $\begin{array}{l}\text { Banco ProCredit, } \\
\text { SA }\end{array}$ & $\begin{array}{l}\text { Associação de } \\
\text { Desenvolvimento Sócio } \\
\text { Económico de Matutuíne } \\
\text { (HLUVUKU) }\end{array}$ & AGRIFUTURO \\
\hline $\begin{array}{l}\text { Banco Internacional de } \\
\text { Moçambique, SA } \\
\text { (Millennium BIM) }\end{array}$ & $\begin{array}{l}\text { Banco Tchuma, } \\
\text { SA }\end{array}$ & $\begin{array}{l}\text { AMODER (Associação } \\
\text { Moçambicana para o } \\
\text { Desenvolvimento Rural) }\end{array}$ & $\begin{array}{l}\text { European Investment } \\
\text { Bank (EIB) }\end{array}$ \\
\hline BTM, SA & $\begin{array}{l}\text { SOCREMO - } \\
\text { Banco de } \\
\text { Microfinanças, SA }\end{array}$ & $\begin{array}{l}\text { Cooperativa de Crédito } \\
\text { Micro-Empresários de } \\
\text { Angónia (CCMEA) }\end{array}$ & $\begin{array}{l}\text { Norwegian } \\
\text { Investment Fund for } \\
\text { Developing } \\
\text { Countries } \\
\text { (NORFUND) }\end{array}$ \\
\hline $\begin{array}{l}\text { Barclays Bank } \\
\text { Moçambique, SA }\end{array}$ & & $\begin{array}{l}\text { Fundo de Desenvolvimento } \\
\text { da Mulher (FDM) }\end{array}$ & $\begin{array}{l}\text { African } \\
\text { Development Bank } \\
\text { (ADB). }\end{array}$ \\
\hline FNB & & $\begin{array}{l}\text { Projecto HOPE } \\
\text { Moçambique }\end{array}$ & $\begin{array}{l}\text { Danish International } \\
\text { Development } \\
\text { Agency (Danida) }\end{array}$ \\
\hline Moza Banco, SA & & $\begin{array}{l}\text { The Hunger Project } \\
\text { Mozambique }\end{array}$ & $\begin{array}{l}\text { European Investment } \\
\text { Bank (EIB) }\end{array}$ \\
\hline
\end{tabular}

Fonte: Adaptado de Grob e Nogueira (2010)

Tendo em conta as instituições que prestam ou fornecem este tipo de serviços e acima de tudo, os tipos de serviços que prestam, torna-se necessário a seguir fazer referência a alguns conceitos que orbitam os serviços financeiros e que particularmente vieram para este trabalho.

Seguro de acordo com Silva (Sd) é a transferência do risco através da qual, o segurado transfere a probabilidade de perda financeira para a Companhia de Seguros.

Risco é "o evento ou acontecimento possível, futuro e incerto", Silva (Sd). No entanto, Brigham e Weston (2000) assumem que risco é a possibilidade de um empréstimo não ser pago conforme prometido.

Leasing é um contrato de locação financeira, com extensão por mais de um ano e exigindo-se uma série de pagamentos fixos, (BREALEY, MYERS \&ALLEN, 2007). 
Crédito é o ato pelo qual uma entidade, agindo a título oneroso, coloca ou promete colocar fundos à disposição de outra, com a promessa desta última os restituir na data de vencimento (LEI 9/2004 de 21 de Julho).

O microcrédito é um crédito concedido para criar auto-emprego através de atividades que criam rendimentos, bem como para a habitação para os pobres, VALGY(2010) apud Grameen Bank. No entanto, neste conceito podemos dar destaque para a camada mais necessitada que é incluída mesmo devido as caraterísticas desse tipo de crédito, que são: os montantes de empréstimos reduzidos, o prazo de concessão bastante curto (até um ano) e os períodos de reembolso também (semanais ou mensais).

Navalha (2010) assevera o microcrédito como sendo a modalidade de financiamento que permite aos pequenos empreendedores aceder ao financiamento alternativo, utilizando uma metodologia própria centrada no perfil e necessidades dos mesmos, e deste modo estimulando pequenas atividades e com isso gerando emprego e renda.

\section{SERVIÇOS FINANCEIROS RURAIS E SUA IMPORTÂNCIA NA PROMOÇÃO DO DESENVOLVIMENTO DA AGRICULTURA FAMILIAR}

O crédito aliado a outras políticas de inclusão desempenha um importante papel na geração de trabalho e renda para a Agricultura Familiar. Ainda gera oportunidades, aproximando o beneficiário das políticas que estimulam investimentos em avanços tecnológicos e melhorias nas estruturas das propriedades ou unidades produtivas, mas, mais ainda, trazendo a modernização do campo também auxilia e estimula sua permanência na agricultura, e fortalece o processo de sucessão na agricultura familiar (ZIGER, 2013).

Para Dall'Agnol (2012), o crédito permite ao agricultor familiar ampliar suas relações com o ambiente socioeconômico, agregando avanços tecnológicos, beneficiando-se da assistência técnica, movimentando o comércio e os serviços, tanto na medida da compra de seus insumos produtivos, quanto na venda de seus produtos produzidos e tendo ainda outros efeitos multiplicadores.

\section{CONTRIBUIÇÃO DOS SERVIÇOS FINANCEIROS PARA O DESENVOLVIMENTO DA AGRICULTURA FAMILIAR}

Negrão (2003) no seu artigo “como induzir o desenvolvimento em África?” apud Valá (2009a), defende que para tal indução, deve-se orientar o investimento para a disponibilização de "dinheiro barato" para o sector empresarial nacional de modo a elevar a procura aos 
pequenos produtores através da agro-indústria. Isto significa que a disponibilização do crédito e dos demais serviços financeiros a um custo baixo que permita ao pequeno produtor obter e restituí-lo dentro do período acordado e na íntegra, vai proporcionar ou gerar mais rendimentos resultantes de uma cadeia de eventos rigidamente respeitados, que no final tem a consequência de desenvolver a agricultura familiar e em último, o meio rural.

Já Dall'Agnol (2012) demonstra que os efeitos multiplicadores da aplicação do crédito refletir-se-ão no aumento da produção das propriedades ou explorações come seremento na economia local, tendo nos gastos dos produtores a renda necessária para impactar positivamente nas relações com outras áreas e setores.

\footnotetext{
O crédito no meio rural tem desencadeado diversas formas de desenvolvimento, fatos verificados na organização social e económica com autonomia e sustentabilidade, o acesso ao crédito de forma qualificada promove o crescimento da produção e diversificação das unidades familiares, nos processos de agregação de valor, industrialização e comercialização, na inclusão social de milhares de habitantes do meio rural. (ZIGER, 2013, p. 10)
}

Verifica-se uma transformação distorcida e regressiva da agricultura, no sentido da configuração de uma estrutura produtiva virada para as exportações, com um padrão de acumulação centrado no estrangeiro e, portanto, com limitado contributo para a industrialização da economia. A agricultura não tem desempenhado a sua função principal na actual fase de desenvolvimento que é o de assegurar a melhoria da dieta alimentar, garantir determinados níveis de segurança alimentar e reduzir a pobreza. A dependência alimentar tem aumentado (MOSCA, 2014, p. 23).

\section{ANÁLISE E DISCUSSÃO DOS RESULTADOS}

A Cooperativa 25 de Setembro, fica localizada em Boane, Província de Maputo, foi fundada nos anossetenta (70), o que significa que ela já funciona a mais dequarenta (40) anos. Actualmente comtrinta e oito (38) membros, sendo as mulheres que constituem a maioria, ela se dedica a produção de culturas como o milho, feijões, beringela, batata, repolho, couves, entre outras, tanto num sistema de rega como em sequeiro, numa área de 40ha.

A Cooperativa é bastante organizada e como qualquer entidade organizada, tem um órgão de direcção que por sinal é presidido por um membro do sexo feminino. As suas atividades são na sua maioria independentes, mas os traços associativos ou cooperativos estão presentes, sendo que estes dividem as suas atividades em grupos de trabalho destacados, 
partilham os custos na contracção de empréstimos e não só. Os empréstimos são contraídos em nome da Cooperativa, mas nem sempre todos os membros se beneficiam, ou seja, pela insuficiência do valor de uma letra contraída, nem todos os membros de uma so vez podem ter acesso ao empréstimo, nesse caso, os empréstimos passam a ser rotativos.

Para o presente estudo foram inquiridos trinta e um (31) produtores agrícolas pertencentes à Cooperativa 25 de Setembro, ou seja, o equivalente a trinta e uma famílias praticantes da agricultura familiar, correspondente ao tamanho amostral da população em estudo.

\section{SERVIÇOS FINANCEIROS RURAIS E SEUS AGENTES FORNECEDORES OU PROVEDORES}

De acordo com os resultados obtidos a partir da aplicação dos questionários e das entrevistas efectuadas, constata-se que os serviços financeiros rurais são inúmeros. Significa deste modo, que os resultados aqui apurados, coadunam certamente com os depoimentos de Grob e Nogueira (2010) apresentando uma série de serviços financeiros que de antemão Amarcy e Massingue (2011) em sincronia com o Banco de Moçambique (2007) já haviam validado. Neste sentido, quer-se concluir que a poupança, o crédito, o microcrédito e o leasing são serviços financeiros existentes no distrito de Boane e particularmente o crédito e o microcrédito (Tabela 1) são os que especialmente os produtores da Cooperativa 25 de Setembro aderem. No entanto, os outros serviços como pode-se notar, "não são acedidos"7 pelos pequenos produtores por razões anteriormente esclarecidas e ainda pela urgência em adquirir e fazer o devido uso dos outros.

Os créditos vem proporcionado tanto a geração de renda, quanto o crescimento econômico apesar de favorecer mais a geração de renda. No entannto, os juros destes créditos são pagos pelos solicitantes ou beneficiários dos mesmos sem que sejam subsidiados à taxas que ascendem os $20 \%$, de acordo com o credor.

Tabela 1: Serviços procurados em função do sexo

\footnotetext{
${ }^{7} \mathrm{O}$ uso dos outros serviços é escasso, o que de acordo com as necessidades de utilização para outros fins não permite fazer essa aplicação de forma constante e comum. É necessário referir que o seguro agrícola em Moçambique ainda continua sendo uma atividade não enraizada.
} 


\begin{tabular}{l|c|c|c}
\hline \multirow{2}{*}{ Qual serviço procurou? } & \multicolumn{2}{|c|}{ Sexo do produtor? } & Total \\
\cline { 2 - 3 } & Masculino (\%) & Feminino (\%) & $(\%)$ \\
\hline Crédito & 19.4 & 16.1 & 35.5 \\
Microcrédito & 29.0 & 35.5 & 64.5 \\
Total & 48.4 & 51.6 & 100.0 \\
\hline
\end{tabular}

Fonte: Adaptado de Grob e Nogueira (2010)

No que respeita aos fornecedores destes serviços, os autores referenciados anteriormente fizeram questão de referenciá-los e bem, sendo que em particular estão as Instituições de micro finança com $63.3 \%$ donde se destaca os bancos e os operadores, seguido dos bancos comerciais $20.4 \%$ e ainda o Fundo de Iniciativa Local ou Fundo de Desenvolvimento do Distrito não menos importante com 16.3\%. Portanto, em conformidade com as estatísticas executadas e aos resultados apurados (Tabela 2), conclui-se que destes fornecedores, os que os produtores da Cooperativa lidam mais são os bancos e operadores de micro finança, tal como Grob e Nogueira (2010) afirmaram.

Tabela 2: Principais fornecedores dos serviços financeiros à Cooperativa

\begin{tabular}{l|c|c|c}
\hline \multirow{2}{*}{ Agentes de serviços financeiros } & \multicolumn{2}{|c|}{ Respostas } & $\begin{array}{c}\text { Porcentagem } \\
\text { de casos }\end{array}$ \\
\cline { 2 - 2 } & Número & Percentual & $32.3 \%$ \\
Bancos Comerciais & 10 & $20.4 \%$ & $25.8 \%$ \\
\cline { 1 - 1 } FIIL/ FDD & 8 & $16.3 \%$ & $100.0 \%$ \\
\cline { 1 - 1 } $\begin{array}{l}\text { Instituições de micro finanças ou } \\
\text { microcrédito }\end{array}$ & 31 & $63.3 \%$ & $158.1 \%$ \\
Total & 49 & $100.0 \%$ & \\
\hline
\end{tabular}

Fonte: Adaptado de Grob e Nogueira (2010)

\section{A IMPORTÂNCIA DOS SERVIÇOS FINANCEIROS COMO PROMOTORES DO DESENVOLVIMENTO DA AGRICULTURA FAMILIAR}

De acordo com os resultados do inquérito, os produtores foram unânimes (97\% dos inquiridos: Tabela 3) em afirmar que os fornecedores dos serviços financeiros rurais mostram abertura em fornecer os serviços. Quanto à atratividade a situação foi contrária em termos de afirmação, 74\% dos inquiridos não vê atratividade nos serviços. Portanto, dizem não haver escolhas ou soluções melhores. 
Tabela 3: Abertura dos prestadores dos serviços financeiros

\begin{tabular}{l|c|c|c|c}
\hline \multicolumn{1}{c|}{ Válido } & Frequência & Percentual & $\begin{array}{c}\text { Percentagem } \\
\text { válida }\end{array}$ & $\begin{array}{c}\text { Percentagem } \\
\text { acumulativa }\end{array}$ \\
\hline Sim (Mais que 50\%) & 30 & 97 & 97 & 97 \\
\cline { 1 - 2 } Não (1\% a 20\%) & 1 & 3 & 3 & 100 \\
\hline Total & 31 & 100 & 100 & \\
\hline
\end{tabular}

Fonte: Trabalho de Campo (2016)

Em relação à importância dos serviços financeiros rurais, não restam dúvidas, o que se pode comprovar a partir dos resultados apurados no inquérito que mostram o quão fundamental são os serviços financeiros para a agricultura familiar nacional. O Ministério da Agricultura (2011) assevera que os serviços financeiros são importantes porque o problema da baixa produtividade agrícola deve-se a aplicação de práticas de cultivo tradicionais e a baixa utilização de insumos, refere que as parcelas são cultivadas manualmente e com utilização mínima de sementes melhoradas, facto que seria facilmente ultrapassado com o fácil acesso e utilização dos serviços financeiros. Salienta ainda que a pobreza rural deve-se, sobretudo ao limitado desenvolvimento da agricultura, deve-se ao limitante acesso ao mercado e à fraca produtividade das culturas alimentares, o que só pode ser ultrapassado com o auxílio dos serviços financeiros.

Carrilho et al. (2002) argumenta que o crédito sazonal, especialmente para fornecer insumos, é fundamental para que os produtores familiares adicionam valor ao nível rural como condição necessária para um crescimento sustentável dos rendimentos e redução da pobreza rural. No entanto, o mesmo pensamento desta solução de melhoria das condições sociais e consequentemente o alcance do desenvolvimento deste meio é partilhado por Valá (2009b).

O gráfico 01 apresenta informações relativa a questão da possibilidade de se praticar a atividade agrícola e assim prosperar sem o suporte dos serviços financeiros rurais. 
Gráfico 1: Possibilidade de desenvolvimento da agricultura familiar desprovido dos serviços financeiros rurais

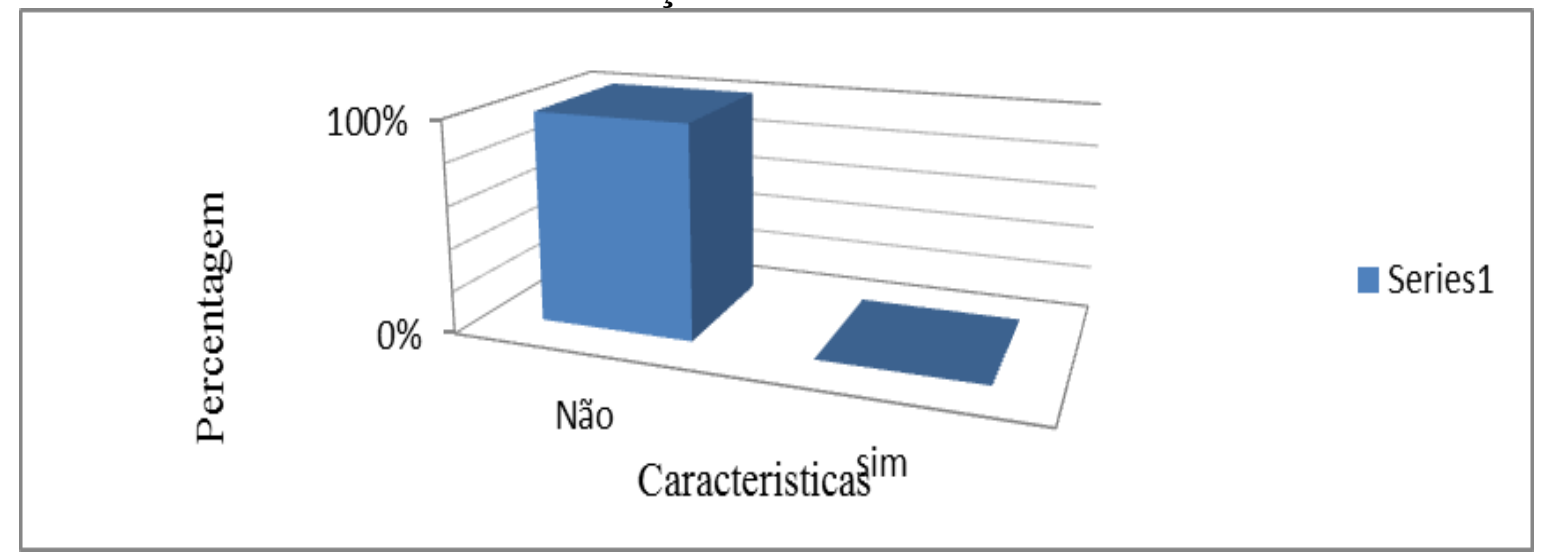

Fonte: Trabalho de Campo (2016)

Os produtores inquiridos afirmaram na generalidade absoluta (100\%) que os serviços financeiros para a agricultura em geral e para a agricultura familiar em especial na realidade rural, estão de tal maneira associados e ou interligados e que se esses fossem separados, seria impossível produzir-se e obter-se rendimentos satisfatórios. Com isto, querem os produtores dizer que não é possível de forma alguma que a agricultura familiar desenvolva-se sem o auxílio dos serviços financeiros rurais.

\section{CONTRIBUIÇÃO DOS SERVIÇOS FINANCEIROS RURAIS PARA A PROMOÇÃO DO DESENVOLVIMENTO DA AGRICULTURA FAMILIAR NA COOPERATIVA 25 DE SETEMBRO DE BOANE}

Dos argumentos dos produtores da Cooperativa, deu a entender que os serviços financeiros contribuem para o alargamento das suas áreas de cultivo, possibilitam a funcionalidade do sistema de bombagem de água para rega, permitem a aquisição de combustível para as atividades de lavoura, aquisição ainda de sementes melhoradas, permite o uso de adubos e defensivos e, permite a contratação de mão-de-obra tanto efetiva como sazonal para dar conta das atividades produtivas (Gráfico 2). Estes depoimentos, se encaixam de maneira sintonizada aos argumentos que os autores fazem, sendo os exemplos Valá (2009a), em que defende a disponibilização do crédito e demais serviços financeiros a custo baixo para permitir gerar mais rendimentos resultantes de uma cadeia de eventos rigidamente respeitados culminando com o desenvolvimento da agricultura familiar. Dall'Agnol (2012) e Ziger (2013) acrescentam como suporte comprovativo de alguns aspectos acima referenciados 
ou evidenciados e ainda acrescentam o aspecto da inclusão social, agregação de valor, industrialização e comercialização.

Gráfico 2: Contribuição dos serviços financeiros para a atividade agrícola Como os serviços financeiros ajudaram a desenvolver a actividade?

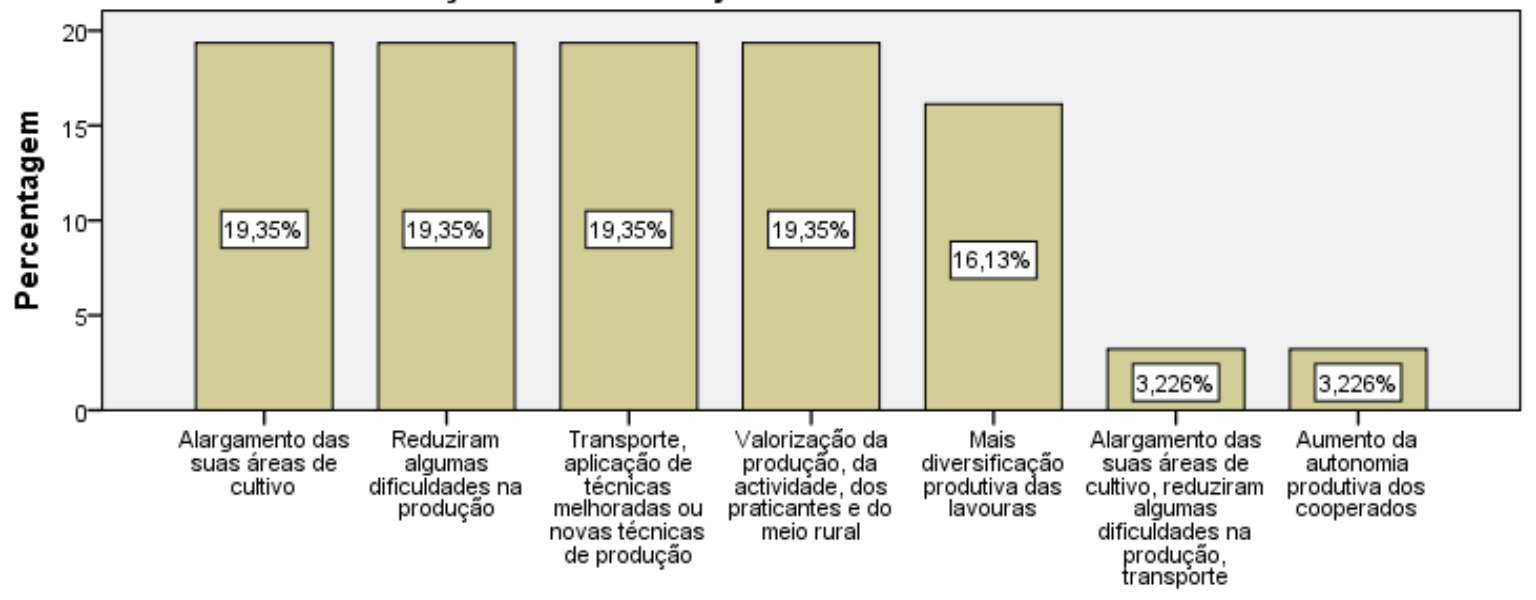

Fonte: Trabalho de Campo (2016)

Mais suporte se nota em Abramovay (1998), exemplificando projetos de desenvolvimento de pequena dimensão em que o acesso ao crédito, mesmo em atividades econômicas tradicionais e aparentemente pouco promissoras gera renda se traduzindo em melhoria na condição de vida para as populações envolvidas com os projetos, e para o nosso caso, os produtores familiares. Contudo, finalizamos com o apoio de Psico (2010) que solidifica a contribuição dos serviços financeiros referindo-se as suas funções essenciais para uma produção mais eficiente e um consumo estável ao nível familiar e para custos de transação mais baixos no mercado. No entanto, permite a redução da fome no seio do agregado familiar, permite o aumento do rendimento familiar e consequentemente melhoria da situação educacional e de saúde do agregado (CONSELHO DE MINISTROS, 2007).

Dos argumentos apresentados pelos produtores da Cooperativa, deu para perceber que os serviços financeiros contribuem para o alargamento das suas áreas de cultivo, possibilitam a funcionalidade do sistema de bombagem de água para rega, permitem a aquisição de combustível para as atividades de lavoura, aquisição de sementes melhoradas, permite o uso de adubos e defensivos e permite a contratação de mão-de-obra tanto efectiva como sazonal para dar conta das atividades produtivas. 
Estes serviços se expressam importantes ainda por no final da época produtiva, contribuírem para um aumento da produção e produtividade à partir do aumento das áreas de cultivo devido a aplicação de técnicas melhoradas ou novas técnicas de produção, fazendo com que os rendimentos da época produtiva sejam satisfatórios, desta maneira, melhora a dieta alimentar dos produtores e o com o resultado da venda da sua produção, são efectuadas poupanças e investimentos em imóveis. Portanto, isso permitiu a redução do problema da insegurança alimentar no seio do agregado familiar dos produtores, aumento do rendimento familiar e consequente melhoria da situação educacional e de saúde do agregado. Outro dos ganhos com o uso dos serviços financeiros rurais é o alargamento do mercado consumidor por parte da cooperativa 25 de Setembro, que permitiu o abastecimento ao mercado local, provincial e da capital do país.

Outro ganho verificado foi o acesso a telefonia móvel por parte dos membros da cooperativa, uma vez que no distrito os serviços de telefonia móvel estão em expansão, onde os membros têm a opção de escolher entre as três operadoras de telefonia móvel existente no distrito e no país. Dizer que estes serviços estãojogando um papel bastante preponderante na comunicação dos produtores entre si, bem como com os parceiros da cooperativa. Contudo, dizer que de um modo geral, a qualidade de vida dos produtores melhorou tendo em conta as conquistas registadas por estes produtores.

\section{CONCLUSÕES}

Realizada a pesquisa, concluiu-se que os serviços financeiros existentes no distrito de Boane, província de Maputo, Moçambique são o crédito, o microcrédito, a poupança e o leasing. No entanto, no caso da Cooperativa 25 de Setembro, os serviços existentes, acedidos e usados são principalmente o crédito e o microcrédito.

Quanto aos respetivos fornecedores, o estudo mostrou a existência de Bancos Comerciais, o Fundo de Investimento de Iniciativa Local ou Fundo de Desenvolvimento do Distrito, as Agências de Desenvolvimento e as instituições de microcrédito ou microfinanças, sendo que para o caso da Cooperativa 25 de Setembro apenas as Agências de Desenvolvimento não as fornecem.

Relativamente a importância dos serviços financeiros para promover $o$ desenvolvimento da agricultura familiar nas zonas rurais, a Cooperativa 25 de Setembro e o distrito numa perspectiva geral, acham muito importante o acesso e utilização de serviços 
financeiros. No que concerne a sua contribuição, os serviços financeiros promovem o desenvolvimento da agricultura familiar na Cooperativa 25 de Setembro.

De um modo geral, provou-se que os serviços financeiros promovem o desenvolvimento da agricultura familiar, na Cooperativa 25 de Setembro em particular e no distrito de Boane, em geral

\section{REFERÊNCIAS}

ABRAMOVAY, Ricardo. Agricultura familiar e desenvolvimento territorial.Revista da Associação Brasileira de Reforma Agrária.28 (1), 2 - 21- Jan/dez de 1998 e jan/ago de 1999.

ALEGRE, Telma Vanessa Nunes G. Cooperativas agrícola e desenvolvimento comunitário no distrito de Boane: $O$ caso das Cooperativas 25 de Setembro e Agro-pecuária de Campoane. 2012. Tese (Mestrado em Desenvolvimento Agrário- Ramo de Desenvolvimento Rural) - Faculdade de Agronomia e Engenharia Florestal, Universidade Eduardo Mondlane, Maputo.

AMARCY, Sofia \& MASSINGUE, Nelson. Desafios da expansão de serviços financeiros em Moçambique. Desafios Para Moçambique, 185-205. 2011. Acesso em http://www.iese.ac.mz.

BREALEY, Richard; MYERS, Stewart \& ALLEN, Franklin. Princípios de finanças empresariais. 8a ed. Madrid: McGraw-Hill Interamericana de Espanha, S.A.U, 2007.

BRIGHAM, Eugene. F.,\& WESTON, J. Fred. Fundamentos da administração financeira. $10^{\mathrm{a}}$ ed. São Paulo: Pearson Makron Books, 2000.

CARRILHO, João; BENFICA, Rui; TSCHIRLEY, David \& BOUGHTON, Duncan. Qual o papel da agricultura comercial familiar no desenvolvimento rural e redução da pobreza em Moçambique. In Paper presented by João Carrilho at a seminar of the Associação Moçambicana de Ciências e Tecnologias, Maputo. 2002. Acesso em http://www.dialogoemprego.org.

CUNGUARA, Benedito \& GARRETT, James. O sector agrário em Moçambique: Análise situacional, constrangimentos e oportunidades para o crescimento agrário. Documento apresentado no "Diálogo sobre a Promoção de Crescimento Agrário em Moçambique. 2011. Acesso em http://fsg.afre.msu.edu.

DALL'AGNOL, Mônia. Crédito Cooperativo do PRONAF e Agricultura Familiar: o caso da Credicaru. 2012. Acesso em https://repositorio.ufsc.br.

GROB, Jane \& NOGUEIRA, André. Financiando Moçambique. $2^{\mathrm{a}}$ ed. Maputo: Swiss Capital Partners Lda e Finantia Lda, 2010.

http://dicionario.sensagent.com.

Leadership Business Group. Acesso em http://www.leadership-bg.com/index.php? 2016

Sociedade e Território - Natal. Vol. 28, N. 2, p. 42 - 56. Jun./Dez. de 2016 
MOÇAMBIQUE. Conselho de Ministros. Estratégia de desenvolvimento rural. Maputo. 2007. Acesso em http://www.nationalplanningcycles.org.

MOÇAMBIQUE. Lei 9/2004, de 21 de Julho. Boletim da República no 29/2004- I

Série.Assembleia da República. Maputo.

MOÇAMBIQUE. Ministério da Agricultura. Plano estratégico para o desenvolvimento do sector agrário(PEDSA). Maputo: Ministério da Agricultura. 2011. Acesso em http://www.open.ac.uk.

MOSCA, João. Agricultura familiar em Moçambique: Ideologias e polítcas. Marginación y mecanismos de integración/resistencia de la agricultura familiar en Mozambique.CESAISEG. 2014. Acesso em http://pascal.iseg.utl.pt/ cesa/index.php/menupublicacoes/workingpapers. p. 34.

NAVALHA, Felisberto Dinis. Moçambique: Reforma financeira e enquadramento das microfinanças. Maputo: Banco de Moçambique. 2010.

PSICO, José A. Tomo. Microfinanças: Solução para o combate à pobreza? Ecolar Editora. 2010.

SILVA, Affonso. Noções básicas de seguros. (S. d). Acesso em http://affonsosilva.com.br.

SITOE, Tomás A. Agricultura familiar em moçambique estratégias de desenvolvimento sustentável. Maputo. 2005.

VALÁ, Salim Cripton. Desenvolvimento Rural em Moçambique: Um Desafio ao Nosso Alcance. Tipografia Peres. Maputo. 2009b.

VALÁ, Salim Cripton. Pobreza, pequenas e médias empresas e desenvolvimento económico dos distritos em Moçambique. In MPD-DNPDR Comunicação apresentada durante a II Conferência do IESE sobre "Dinâmicas da Pobreza e Padrões de Acumulação Económica em Moçambique”, Maputo. 2009a. Acesso em http://www.iese.ac.mz.

VALGY, I. I. C. I. Microfinanças em Moçambique: Estudo do perfil do utilizador na Cidade de Maputo. Maputo: Banco de Moçambique. 2010.

ZIGER, Vanderley. Crédito Rural e a Agricultura Familiar: desafios, estratégias e perspectivas. 2013. Acesso em http://infocos.org.br.

Recebido em Agosto de 2016

Aprovado em Novembro de 2016

Publicado em Dezembro de 2016 